\title{
A Megaigreja Hillsong no Brasil: a constituição de um campo religioso transnacional entre o Brasil e a Austrália
}

\author{
Hillsong arrives in Brazil: building a transnational religious \\ field between Brazil and Australia
}

\author{
Cristina Rocha ${ }^{a}$
}

Resumo O Brasil é o maior país pentecostal do mundo e é sede de várias megaigrejas. No entanto, a megaigreja australiana Hillsong escolheu a cidade de São Paulo para estabelecer uma de suas filiais em 2016. Neste artigo investigo as conexões transnacionais que propiciaram a chegada da Hillsong no Brasil. Defendo que a intensa globalização das últimas duas décadas (particularmente as novas tecnologias de informação e comunicação) e o desejo de fazer parte do "Primeiro Mundo" tiveram papel fundamental na presença da megaigreja no imaginário dos jovens cristãos brasileiros, o que eventualmente levou a igreja a estabelecer uma filial no país. Em particular, analiso a existência de um campo religioso transnacional entre Austrália e Brasil. O conceito de campo religioso transnacional leva em conta a maneira como instituições religiosas globais afetam a vida quotidiana dos imigrantes, daqueles que ficam para trás e daqueles que retornam.

Palavras-chave Hillsong; Transnacionalismo; Globalização; Brasil; Austrália.

Abstract Brazil is the largest Pentecostal country in the world and is home to several megachurches. However, the Australian megachurch Hillsong chose the city of São Paulo to establish one of its branches in 2016. In this article I investigate the transnational connections that led to the arrival of Hillsong in Brazil. I argue that the intensification of globalization processes of the past two decades (particularly new Information and Communication Technologies), and a desire to be part of the Global North played a key role in the presence of the megachurch in the imagination of young Christian Brazilians, which eventually paved the way for the megachurch to be established in the country. In particular, I analyze the existence of a transnational religious field between Australia and Brazil. This concept accounts for the way global religious institutions affect the everyday life of immigrants, those who stay behind, and those who return.

Keywords Hillsong; Transnationalism; Globalization; Brazil; Australia.

a Antropóloga, pesquisadora do Australian Research Council e diretora do Centro de Estudos de Religião e Sociedade na Western Sydney University, Austrália. É também editora da revista Journal of Global Buddhism e da coleção Religion in the Americas, da editora Brill. 


\section{INTRODUÇÃO}

Na última década, a megaigreja australiana Hillsong tornou-se um fenômeno global. Após estabelecer filiais bem-sucedidas em muitas cidades europeias, tais como Londres, Estocolmo, Paris, Amsterdã, Barcelona, Berlim, e até na Cidade do Cabo na África do Sul, estabeleceu-se nos EUA, quando os dois filhos de Brian Houston, o pastor sênior da igreja, abriram filiais em Nova Iorque e Los Angeles em 2011 e 2014. Em 2015, a Hillsong partiu para a conquista da América do Sul. A fim de fundar uma filial em Buenos Aires, o casal de pastores australianos filhos de pais argentinos, Chris e Lucy Mendez, mudou-se para a cidade em julho de 2015. Em novembro do mesmo ano, a Hillsong Buenos Aires abriu suas portas. Entretanto, desde sua chegada a Buenos Aires, Chris Mendez também começou a viajar por todo o Brasil para preparar o terreno para a implantação da filial na cidade de São Paulo, que finalmente começou a funcionar em outubro de 2016.

Em São Paulo, muitos jovens brasileiros estavam ansiosamente à espera de uma chamada para se voluntariar na igreja. Muitos deles haviam estudado no International Leadership College, o seminário da Hillsong em Sydney. Outros eram fãs da Hillsong United, a banda da igreja que várias vezes percorreu o país em turnê e é famosa nos círculos evangélicos. Há anos estes jovens imploravam à igreja e à banda para virem para o Brasil - pessoalmente, durante shows da banda, ou nas redes sociais. Com efeito, uma ex-vocalista e compositora da Hillsong me disse que a banda tinha apelidado a insistência com que os jovens brasileiros pediam para a banda retornar ao Brasil e para a igreja abrir uma filial no país de "o efeito venham para o Brasil".

Assim, desde fevereiro de 2015, quando foi divulgada a notícia de uma futura filial em São Paulo, houve um frenesi de mensagens e fofocas nas redes sociais brasileiras e até mesmo na mídia secular, que apelidou a Hillsong de "a igreja de Justin Bieber", depois que o cantor começou a frequentar a filial de Nova Iorque. Em maio de 2015, quando o site oficial da Hillsong São Paulo no Facebook anunciou a primeira noite de informações sobre a igreja numa casa de shows nos Jardins, um bairro de classe média alta de São Paulo, o site foi inundado por comentários e perguntas. Muitos indagavam se o evento seria pago e se necessitavam reservar lugar, confundindo a noite de informações com um show da banda. O evento lotou rapidamente e uma segunda sessão de informações for organizada para a mesma noite. Alguns meses mais tarde foi anunciada mais uma noite de informação e a igreja novamente teve que marcar duas sessões seguidas. Quando em maio de 2016 o pastor sênior, Brian Houston, compareceu a uma destas noites, as filas na porta do Áudio Clube, onde se realizaria o evento em São Paulo, começaram a se formar 
três horas antes da hora marcada. Muitos haviam viajado de diversas partes do país para o evento. Naquela noite duas mil pessoas conseguiram entrar e três mil ficaram de fora. Todos esses eventos foram organizados por uma equipe brasileira local composta de ex-alunos do seminário da Hillsong e um grupo crescente de voluntários treinados por eles. No palco, os pastores australianos eram sempre auxiliados por líderes da equipe local, que traduziam suas explicações sobre a igreja e suas pregações.

Enquanto isso, o anúncio de que a Hillsong estava chegando ao país causou tanto rebuliço em círculos evangélicos brasileiros que o pastor Chris Mendez iniciou uma estratégia de relações de boa vizinhança. Ele começou a viajar por todo o Brasil para se reunir com pastores locais, pregar em suas igrejas e assegurar-lhes que a Hillsong não pretendia atrair os jovens de suas congregações. Cuidadoso, ele sempre afirmava o mesmo nas noites de informação, em suas visitas a outras igrejas e em entrevistas na mídia. Por exemplo, durante a primeira noite de informação em maio de 2015, Mendez disse:

\footnotetext{
Não estamos vindo para São Paulo achando que a igreja seja uma resposta para alguma coisa. A resposta é Jesus. Uma igreja como a Hillsong, que é muito conhecida - muitos de vocês estão aqui porque conhecem nosso grupo de louvor - empolga as pessoas. Mas se você está plantado em outra igreja, por favor, não deixe sua igreja porque a Hillsong está vindo para São Paulo. A melhor coisa que você pode fazer para o Reino de Deus é continuar plantado. A Palavra diz: “Aqueles que estão plantados na casa de Deus irão florescer”. Não estamos vindo para construir uma igreja que vai tirar cristãos de outras igrejas; estamos vindo para construir uma igreja onde o perdido possa ser salvo em uma cidade com milhões de habitantes (NovaEs, 2015).
}

Como podemos ver, Mendez estava preocupado em desviar o foco da Hillsong para Jesus e, ao fazê-lo, reafirmar o valor de outras igrejas brasileiras (não tão "modernas") como um caminho igualmente válido para Jesus. Mas o fato de que Mendez teve que fazê-lo com tanta frequência mostra o imenso apelo e celebridade da "marca” Hillsong, que já fazia parte do imaginário da juventude cristã brasileira antes da igreja chegar ao país. Como uma igreja australiana pôde se tornar tão conhecida e reunir tantos "fãs" no Brasil, o maior país Pentecostal do mundo e que possui suas próprias megaigrejas (Freston, 2001, 2004; MARIANO, 2010)? Porque tantos jovens brasileiros viajam para a Austrália para estudar no International Leadership College da Hillsong e participar de seus cultos e conferências? 
Neste artigo investigo as conexões transnacionais que tornaram possível a chegada da Hillsong ao Brasil. Igualmente, analiso como um campo religioso transnacional entre Austrália e Brasil está sendo criado. Este conceito dá conta de como instituições religiosas globais afetam a vida quotidiana dos imigrantes, daqueles que ficam para trás e daqueles que retornam. É importante notar que este campo religioso transnacional entre Austrália e Brasil é circular: os fluxos partem de ambos os polos e movem-se nas duas direções. Se jovens e pastores brasileiros vão a Sydney para frequentar e aprender com a Hillsong, a própria igreja agora está chegando ao Brasil com suas práticas, crenças, rituais e estratégias.

Meu argumento é que a fascinação pela Hillsong é uma consequência de uma assimetria de poder entre o Norte e Sul Globais. Neste artigo demonstro que a intensa globalização das últimas três décadas e um desejo de ser parte do Norte Global têm um papel fundamental na vontade de muitos jovens de classe média brasileiros de viajar para a Austrália e frequentar a Hillsong. No imaginário destes jovens, o status da Austrália como uma nação de "Primeiro Mundo" sobrepõe-se a "marca" da Hillsong, construída como "competente, confiável, eficiente e bem sucedida” (Riches, 2010, p. 149). Como tal, a Austrália e a Hillsong ofereceram a estes jovens a oportunidade de se tornar cosmopolita, algo intensamente desejado pela classe média brasileira (RochA, 2006). Ao frequentar ou estudar na Hillsong podem aprender inglês, conhecer australianos e outros estrangeiros e viver um tipo de pentecostalismo que é global, divertido, emocionante e mais ligado à cultura jovem do que o pentecostalismo no Brasil. Mais ainda, é uma oportunidade de frequentar uma igreja frequentada por celebridades estrangeiras.

Nesta pesquisa, utilizo material coletado durante três anos de trabalho de campo multi-situado na Austrália e no Brasil. Na Austrália, fiz observação participante semanalmente nos cultos e connect groups $^{1}$ da Hillsong frequentados por brasileiros. Também participei de duas conferências da megaigreja em Sydney e entrevistei tanto brasileiros que estudavam no College como aqueles que apenas frequentavam os cultos de domingo e os connect groups. Além disso, fiz entrevistas com a vice-diretora e os professores do College. No Brasil, participei de cultos de igrejas ligadas à Hillsong (seus pastores haviam participado das conferências em Sydney ou haviam estudado no College) e entrevistei pastores e jovens que haviam estudado no College ou frequentado a megaigreja e que haviam retornado ao país.

1 Connect groups são pequenos grupos de pessoas que fazem parte da igreja e se reúnem semanalmente ou quinzenalmente na casa de um líder não só para estudar a bíblia, mas também para apoiar uns aos outros, e sentir-se em família. 
Neste artigo, uso pseudônimos para todos os entrevistados para garantir sua privacidade, a não ser para o pastor Chris Mendez, pois ele é uma figura pública.

\section{A COMUNIDADE BRASILEIRA NA AUSTRÁLIA}

Desde o início do século XXI, a Austrália tornou-se um destino privilegiado para os brasileiros de classe média urbana. Em sua grande maioria, eles são jovens entre 20 e 30 anos, que vão ao país para estudar inglês e posteriormente tentam a residência permanente (CCBV, 2016; Duarte, 2005; Rocha, 2006, 2008, 2009, 2013, 2014; Wulfhorst, 2011, 2014). A cultura de praia e surf da Austrália, a segurança nas ruas, a língua inglesa, a economia forte, o status de primeiro mundo e a possibilidade de trabalhar legalmente meio-período e de conseguir residência depois dos estudos são diferenciais que atraem os jovens brasileiros para a Austrália ${ }^{2}$. Atestando sua posição de classe e idade, é de se notar que a maioria destes jovens não se refere ao processo de mudança para a Austrália como "imigração", mas sim como "fazer intercâmbio", isto é, um rito de passagem, uma aventura em que eles se tornam adultos. Com efeito, esta é a primeira vez em suas vidas que vivem fora da casa dos pais e do Brasil e muitos aprendem a cozinhar, limpar a casa, fazer um orçamento mensal e trabalhar na Austrália. Acima de tudo, os resultados de minha pesquisa mostram que o que estimula a viagem é um desejo de se tornar parte do "Primeiro Mundo" (RochA, 2006, 2008, 2009, 2013, 2014).

Um número preciso de brasileiros na Austrália é difícil de ser calculado, pois diferentes órgãos de governo estimam números díspares. Por exemplo, o censo australiano estimou uma população de 11.404 brasileiros em 2011, mas naquele mesmo ano o Ministério da Educação do governo australiano estimou um total de 15.285 estudantes brasileiros

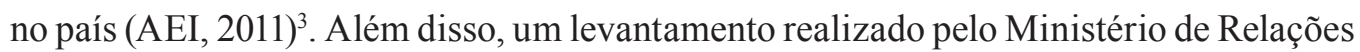
Exteriores do governo brasileiro avaliou haver 27.000 brasileiros na Austrália em 2015 (MRE, 2015) e, em 2016, o cônsul geral do Brasil em Sydney estimou a população brasileira no país em 70.000, calculando o número de passaportes emitidos, títulos de eleitor transferidos, cidadãos registrados e visitas ao consulado.

Com certeza, sabemos que o Brasil foi o sexto país com maior número de estudantes na Austrália, com 17.267 alunos matriculados em 2015, atrás apenas da China, Índia, Vietnã, Coreia e Malásia. Desse total, 11.971 estudantes tinham entre

2 Os Estados Unidos, um polo tradicional de imigração de brasileiros, não permite que estudantes trabalhem legalmente. $\mathrm{O}$ único outro país que permite o trabalho de estudantes é a Irlanda e por isto há um número crescente de jovens brasileiros rumando para lá.

3 Uma explicação para a menor população de brasileiros encontrada pelo censo é que brasileiros são relutantes completar os formulários do censo devido a uma desconfiança generalizada em relação ao aparato de estado (DAMATta, 1984; Hess; DAMATTA, 1995; SAllas; Bega, 2007). Soma-se a isto o fato de que uma grande parte deles não é residente permanente e assim não se dá conta da necessidade de responder ao censo. 
20-29 anos de idade e 3.141 tinham entre 30-34 anos de idade (DET, 2015). Claramente, esta é uma população jovem. Além disso, quase a metade eram mulheres (47,5 \%), o que mostra que esta imigração não é de uma família nuclear, onde o homem sai do país primeiro para preparar o terreno para uma futura imigração da esposa e filhos. A maioria deles já tem ensino superior ou trancou a matrícula da universidade para ir à Austrália. Eles viajam principalmente para estudar inglês e utilizam agências de intercâmbio para planejar a viagem. De fato, em 2015 o Brasil era, depois da China, o segundo maior país por número de estudantes no setor de cursos intensivos de inglês para estrangeiros (ELICOS, English Language Intensive Courses for Overseas Students). Depois de um período de estudos de língua, eles se matriculam em escolas vocacionais (VET, Vocational Education and Training), para poder permanecer no país e na esperança de serem "patrocinados" por seus chefes e tornarem-se residentes permanentes. $O$ fato de terem educação universitária, poderem viajar no exterior e pagar por cursos de inglês e vocacionais mostra que estes jovens pertencem à classe média no Brasil. Mas além de praias, língua inglesa e vida sem criminalidade, a Austrália também tem a sede mundial da megaigreja Hillsong.

\section{A MEGAIGREJA HILLSONG}

A Hillsong é um fenômeno evangélico mundial. A igreja foi fundada pelo casal neozelandês Brian e Bobby Houston em 1983 num bairro de classe média baixa ao noroeste de Sydney. Atualmente, a Hillsong é a maior igreja do país com mais de 30.000 pessoas frequentando suas filiais em todo o país nos fins de semana. É uma igreja pentecostal que faz parte da Assembleia de Deus na Austrália, hoje chamada de "Igrejas Cristãs Australianas". Sua missão é trazer pessoas para dentro da igreja, pois acredita que a partir daí elas se converterão e se transformarão ao serem "trabalhadas" pelo Espírito Santo. Para realizar sua missão, a Hillsong usa uma linguagem híbrida, secular e religiosa. Assim, ela é uma igreja "descolada", onde os cultos são shows de rock em salas escuras, com telões, luzes, câmeras. Os pastores têm tatuagens, falam informalmente e, como a congregação, se vestem à moda hipster (jeans rasgados, camisetas compridas cortadas na manga, jaquetas de couro, colares e botas). Muitas vezes, música secular é tocada no saguão da igreja, onde há um café e uma loja vendendo os últimos livros do pastor sênior e sua esposa e de outros pastores estrangeiros famosos, CDs das bandas, DVDs dos cultos, camisetas com dizeres cristãos, e outras lembrancinhas (cadernos, canetas, bolsas, etc.). Também organiza encontros e festas em bares e pubs para os jovens da congregação e para novatos se inteirarem da igreja. A Hillsong possui 
logotipo, lema, missão e publica um relatório financeiro anual como qualquer outra empresa que preza a transparência. Seu seminário ensina liderança, usando linguagem e conteúdo vindos de cursos de teologia e administração de empresas. Ela lidera uma rede global de igrejas e pastores, a "Hillsong Network", que recebe seus materiais didáticos, treinamento e estratégias online, através de webinar, e durante suas conferências.

Mas o carro-chefe que tornou a pequena igreja fundada em 1983 em uma megaigreja global foi o sucesso extraordinário de sua banda de louvor Hillsong United, que já ultrapassou a marca de 16 milhões de álbuns vendidos no mundo. Suas músicas estão traduzidas em várias línguas e são cantadas em igrejas em todo o mundo. Sua fama é tão grande que, em 2015, ela recebeu o Billboard Music Awards de melhor artista cristão. Em 2016, enquanto a igreja abriu um canal de TV nos Estados Unidos e lançou um aplicativo para celulares, a banda foi tema do documentário "Hillsong: Let Hope Rise", dirigido por Michael Warren, um diretor de cinema de Hollywood conhecido por seus filmes sobre músicos americanos como Nicki Minaj e Jay-Z. A estreia do filme foi nos moldes hollywoodianos: os integrantes da banda, pastores e outras personalidades cristãs eram filmados e entrevistados enquanto entravam no cinema por um tapete vermelho. Tudo era transmitido em tempo real pelo site da Hillsong no Facebook para milhões de pessoas no mundo todo. Isto mostra seu cuidado com o marketing, seu foco em novas tecnologias, culturas de celebridade e juventude e seu apelo global.

\section{A HILLSONG NO BRASIL: FAMOSOS E FÃS}

Como em outras partes do mundo, a Hillsong chegou ao Brasil pela primeira por meio de sua música gospel. Após a explosão mundial da música "Shout to the Lord" e do álbum com o mesmo nome, gravados pela vocalista Darlene Zschech com a banda Hillsong United em 1994, Ana Paula Valadão e sua a banda Diante do Trono gravaram a versão brasileira do álbum, que denominaram "Aclame ao Senhor", no ano 2000. Logo, outras bandas gospel brasileiras começaram a traduzir e gravar álbuns inteiros de músicas da Hillsong United, enquanto igrejas locais frequentemente faziam suas próprias traduções para serem cantadas na igreja. Por sua vez, os jovens destas igrejas disseminaram estas músicas, mostrando CDs e DVDs da Hillsong para seus amigos. A partir de 2006, Darlene Zschech e a banda Hillsong United começaram a fazer turnês pelo país e a participar dos shows da "Marcha para Jesus", um evento evangélico global anual que acontece em várias cidades do Brasil, sendo que o maior atrai em média três milhões de pessoas em São Paulo. Neste interim já havia fã-clubes da banda no Brasil e muitas comunidades 
de fãs nas mídias sociais, primeiro no Orkut (como, por exemplo, a comunidade "Eu Amo a Hillsong”) e depois no Facebook.

Muitos dos jovens que eu entrevistei haviam ido a estes shows como adolescentes depois de ouvir fitas ou CDs da banda dados a eles por seus amigos e membros da família. Disseram-me que isto despertou a vontade de ir para a Austrália. Paula é um bom exemplo disso. Aqui ela explica como descobriu sobre a Hillsong:

Uma coisa que me influenciou muito foi a Hillsong mesmo, a gente conheceu a Hillsong eu tinha 10, 11 anos. A minha prima chegou um dia em casa com um CD que ela copiou de um filho de um pastor que ela conheceu. Aquele CD "Shout to the Lord", que eu lembro até hoje. Aliás, aquela época vinham poucos CDs para o Brasil, acho que veio esse e depois começou a vir outros, né? E aí a gente ouviu as músicas e foi uma experiência muito marcante pra mim. Eu não entendia o inglês ainda da letra, mas eu fui captada de alguma forma, com louvor, com a adoração. Depois de conhecer a Hillsong, era só Hillsong [que eu tocava] o dia todo. $\mathrm{E}$ a gente reconheceu algumas músicas que a gente cantava na igreja em português, que a gente nem sabia que era versão. Então a gente falou assim: “Nossa, então essa igreja já tem as músicas que a gente canta!”. Então ela já é referência há muitos anos e a gente nem sabia!

Depois disso, Paula e sua prima pesquisaram sobre Hillsong na Internet e descobriram que na verdade era (não só uma banda), mas uma igreja na Austrália. Ela começou a procurar outros CDs, mas era muito difícil encontrá-los porque eram importados. Alguns meses depois, ela finalmente encontrou e comprou um DVD da Hillsong em uma loja cristã em São Paulo. O DVD explicava sobre a igreja, incluía pregações de Brian Houston e mostrava cenas dos cultos e eventos de jovens. Os pais de Paula eram pastores e ela começou a pensar que poderia transformar sua igreja. Ela me contou: "[Eu vi que] Os próprios jovens compunham, gravavam CDs, a gente começou a ver aquilo como um sonho, um sonho de Deus, um sonho ministerial pra nossa igreja!”.

O impacto que a Hillsong teve em sua vida foi tão grande que ela começou a estudar inglês aos 12 anos de idade, para que pudesse um dia viajar para a Austrália, estudar no College da Hillsong e trazer o que ela aprendeu para a sua igreja. É de se notar que Paula mistura seu amor pela Hillsong e pela Austrália, usando a palavra "fã" nas suas instâncias: 
Eu tinha todos os DVDs da Hillsong. E na internet eu pesquisava a Austrália toda, eu tinha várias fotos, eu tinha estudado já a cultura, os costumes deles, curiosidades de lá, os animais exóticos. Já tinha estudado praticamente tudo da Austrália, eu virei fã , fã mesmo. (risos) Aquelas fãs adolescentes. Toda adolescente tinha um ídolo de cantor assim? O meu era a Hillsong, eu era fã. Sabia os nomes dos integrantes, e aí eu e minha prima pesquisávamos tudo na internet, na época era mais Myspace que era a rede social, até os perfis deles no Myspace a gente via! Eu acompanhava os perfis, onde eles iam fazer show, quantos anos eles tinham, a família, que aí eu descobri que o Joel era filho do pastor Brian!

Quando a banda finalmente veio a São Paulo em 2006, ela e a prima foram ao show: "Chegamos cedo, ficamos na frente, e aí todos os integrantes que vieram a gente sabia quem eram, os nomes [...] Que nem fã que vai ver a banda que a gente gosta”. No ano seguinte, Darlene Zschech deu um show no Rio, e ela e alguns amigos fizeram a viagem de 5 horas de ônibus de São Paulo ao Rio de Janeiro no dia do show e voltaram para casa na mesma noite. É significativo que a internet desempenhou um papel importante para elas se conectarem com outros jovens brasileiros que também amavam a banda. Paula disse:

No Orkut tinha as comunidades. E aí tinha essa comunidade da Hillsong, que vários brasileiros iguais a mim, que tinham esse sonho, ficavam trocando conversas nas comunidades. Inclusive, depois dos shows, a gente fazia encontro com o pessoal do Orkut no show. E a gente foi ampliando amigos, amigos em comum que também sonhavam em ir para a Austrália, que gostavam da Hillsong.

Mais uma vez, Paula sobrepõe a Austrália e a Hillsong, transformando as duas num sonho. A fim de realizar este sonho, aos quinze anos começou a trabalhar para economizar dinheiro para a viagem. Finalmente, quando fez dezenove anos, em 2009, partiu para a Austrália.

Claramente, aqui podemos ver o papel da cultura jovem e de celebridade na atração de Paula e outros jovens brasileiros pela Hillsong e Austrália. A cultura da celebridade é uma parte importante do marketing da Hillsong e é algo que necessita ser administrado cuidadosamente. De acordo com Wagner (2013, p. 22):

A estrutura transnacional da Hillsong dita que deve usar imagens de massa mediatizadas e tornar seus músicos celebridades para comunicar seus valores de forma eficiente. No entanto, deverá fazê-lo em um contexto cristão evangélico 
em que só Jesus é "famoso" e celebridades são muitas vezes vistas com desconfiança. A “celebridade” de seus músicos, portanto, deve ser gerida com cuidado. Para fazer isso, a Hillsong promove seus valores e a sua mensagem através de um grupo de líderes de adoração bem conhecidos que também fazem parte do círculo restrito da igreja. Darlene Zschech, talvez a mais conhecida líder de louvor da Hillsong, é associada com a marca Hillsong - ela e a igreja estão indissoluvelmente associadas uma com a outra4 ${ }^{4}$

A cultura da celebridade é ainda mais potente quando chega em inglês (a língua franca da globalização) e em fluxos que partem dos países desenvolvidos para aqueles em desenvolvimento. Peggy Levitt (1998, p. 927) cunhou o termo "remessas sociais" para descrever "ideias, comportamentos, identidades e capital social que fluem dos países de recepção (de imigrantes) para os países que enviam imigrantes". Ela argumenta que

O impacto das remessas ocorre em função de diferenças de tamanho e de poder entre os países de envio e recepção de imigrantes. Alguns destinatários serão mais receptivos às remessas porque eles querem ser "ricos" e "modernos" como aqueles países de recepção de imigrantes (LEvitT, 1998, p. 940).

Essa é uma das razões pelas quais, para muitos jovens brasileiros, ir à Austrália para participar do culto ou da conferência da Hillsong ou estudar em seu College torna-se "um sonho". Um ex-estudante brasileiro do College da Hillsong que hoje reside em Sydney notou este fascínio em seu blog chamado Brasil-Austrália:

No Brasil há um imenso deslumbramento em relação à Hillsong. Criou-se até uma espécie de idolatria à igreja, ao louvor e até a alguns pastores e cantores, idolatria esta em nenhum momento incentivada pela igreja e que praticamente não existe aqui. Com este deslumbramento muitos brasileiros decidem vender o carro, pegar dinheiro emprestado com o pai, tio e avô e vir pra cá fazer um dos cursos do seminário da Hillsong (Strazzery, 2011).

Antônio, hoje pastor de uma igreja brasileira em Sydney, entende bem esta situação. Músico, sempre foi fã da banda United. Quando foi à Austrália pensava

4 Atualmente Darlene Zschech já saiu da banda, mas os novos integrantes, particularmente a vocalista Taya Smith e o guitarrista Joel Houston, filho dos pastores sêniores, são igualmente famosos. 
em estudar inglês e tinha um sonho de tocar na Hillsong. Logo que chegou começou a frequentar a megaigreja. Como muitos outros brasileiros, fez o teste de música para tocar no culto e estava na fila já há bastante tempo esperando o chamado. Quando perguntei o que ele sentiu quando foi à Hillsong pela primeira vez, ele respondeu: "Eu acho que 90\% dos brasileiros que entram lá, choram na primeira vez. Porque acho que é meio emocionante. E nem é tanto assim do cristianismo, em relação a Deus...”. Na análise bastante acurada de Antônio, a emoção que os brasileiros sentem não irrompe por estarem numa igreja com Deus, mas no lugar com o qual tanto sonharam. Ela está relacionada à aura da Hillsong, por chegarem ao fim da peregrinação e finalmente estarem presentes na sede autêntica da igreja. A razão para isto é certamente a cultura de celebridade associada à Hillsong. Na entrevista ele diz que a Hillsong é tão presente no imaginário brasileiro, que outras igrejas estão copiando a igreja australiana: "Mas hoje em dia tem igrejas imitando a Hillsong, até o logotipo! Tudo, a maneira de falar, de agir. Então eles usam o estilo de roupa, o estilo de tocar, tudo igual".

Em meu trabalho de campo no Brasil constatei este fato. Por exemplo, a igreja Lagoinha de Belo Horizonte, uma das maiores do Brasil, mudou seu logotipo, pintou as paredes da igreja de negro e instalou luzes de casa de show para iluminar a plataforma (o palco) num esforço consciente para se assemelhar à Hillsong. A Brasa Church, de Porto Alegre, é administrada e frequentada por jovens que se vestem e tocam músicas de louvor semelhantes às músicas da Hillsong. Vemos a influência da língua inglesa já no fato de se denominar "Church", não igreja. A Igreja no Cinema (INC) de Curitiba, igualmente administrada e frequentada exclusivamente por jovens, faz seus cultos em cinemas de shopping centers da cidade e também se espelha na Hillsong. Seus pastores frequentemente participam da conferência anual da Hillsong em Sydney. Quando perguntei a Antônio o porquê desse desejo de copiar a igreja australiana, ele respondeu:

Acho que a palavra cool é que resume mais ou menos essa situação, acho que o brasileiro começou a ver: "Pô tem um negócio cool, tem um negócio moderno lá fora.” E então juntou o cool com igreja né, uma igreja moderna, uma igreja cool.

Aqui vemos como a posição do Brasil como país do Sul Global e um desejo de modernidade que parece estar localizada no Norte Global influencia qual o tipo de Pentecostalismo importamos. É de se notar que este é um pentecostalismo importado pela classe média, com cultos desprovidos de rituais ostensivamente "mágicos", tais como glossolalia e cura, e centrado na emoção do louvor e no amor de Jesus 
e para com o próximo (Koenrsen, 2016). Apesar da sua heterogeneidade interna, poderíamos dizer que esse setor da sociedade valoriza a educação e a cultura e o consumo de bens do Norte Global como um caminho para a mobilidade social e cosmopolitismo. Assim, aspiram adquirir capital cultural (Bourdieu, 1986) ao aprender inglês, vestir-se, tocar e cantar como os jovens da megaigreja australiana.

Tendo isso em mente, fica claro por que o status da Hillsong no Brasil foi reforçado quando a megaigreja estabeleceu filiais nos Estados Unidos. Sabemos que os brasileiros se preocupam em se inteirar e copiar as novas tendências norte-americanas. Após Justin Bieber e outras celebridades começarem a participar dos cultos de igreja em Nova York e Los Angeles, celebridades brasileiras também começaram a fazer o mesmo e postar suas experiências para seus fãs em tempo real nas mídias sociais. Um bom exemplo é o jogador brasileiro David Luiz. Quando jogava para o Chelsea, ele se converteu e foi batizado na Hillsong de Londres. Depois que foi contratado pelo Paris Saint-Germain, ele frequentou a filial de Paris. Desde sua conversão ele tem postado fotos e comentários de suas atividades na igreja regularmente nas mídias sociais para seus fãs no Brasil. Outras celebridades locais, as amigas Bruna Marquezine (uma atriz de novela da rede Globo e ex-namorada do jogador de futebol Neymar) e Stephannie Oliveira (modelo e filha do ex-jogador de futebol Bebeto) também visitaram a Hillsong quando foram a Los Angeles. Durante o culto elas postaram vídeos e fotos no Instagram para seus fãs (CHAGAS, 2014).

\section{A DIFÍCIL READAPTAÇÃO NO RETORNO}

Em entrevistas, os jovens brasileiros que estudaram ou serviram na megaigreja australiana sempre me contam de sua frustração quando retornam ao país e tentam mudar suas igrejas. Geralmente isso ocorre porque, em contraste com a Hillsong, a maioria das igrejas pentecostais brasileiras é bastante conservadora, sua congregação contém mais famílias do que jovens, e os pastores são mais velhos e dão pouca ou nenhuma autonomia aos jovens na administração da igreja e dos cultos. Além disto, elas não estimulam uma cultura jovem durante os cultos. Por exemplo, as igrejas brasileiras são bem iluminadas com paredes brancas; os cultos são longos, com uma duração de até três horas; os pastores e congregação vestem-se formalmente e não possuem tatuagens ou piercings; não se pula e dança na igreja; a pregação é voltada para a congregação mais velha.

Por outro lado, na Hillsong, a igreja é tipicamente um teatro escuro, os cultos são mais curtos (exatamente de noventa minutos) e há muito entretenimento. Como mencionei anteriormente, os cultos são quase que um show de rock (com 
luzes coloridas no palco, câmeras que filmam a plateia e a banda e transmitem estas imagens em telas enormes em tempo real, pessoas dançando, pulando e filmando a banda com seus telefones celulares) e há videoclipes extremamente profissionais (contendo as novidades da igreja e testemunhos) entre o louvor, oferta e pregação. Os pastores e a congregação usam roupas informais e pregam em um estilo informal, com grande interação com a congregação. Muitas igrejas brasileiras também dão um lugar especial para rituais de cura, exorcismo e glossolalia, o que não ocorre na Hillsong durante o culto, pois seu foco é na música de louvor e no uso da bíblia para guiar os fieis no dia a dia.

Como resultado dessas diferenças, Roberto (que estudou por três anos no College) me disse em uma entrevista que, dos seus trinta amigos que haviam retornado após servir ou estudar na Hillsong, apenas três ou quatro ainda frequentavam igrejas. Seus amigos explicavam ter saído de suas igrejas desta maneira: "É porque ainda não encontrei uma igreja que é como eu”; "Eu tive problema com o meu pastor"; "Eu voltei para minha igreja e não foi nada como eu queria e agora estou meio perdida"; "Estou indo a igrejas diferentes aqui e ali”. Outro estudante que entrevistei, que havia retornado ao Brasil, confirmou isto quando ele me disse: "[Quando voltei] os jovens [estavam] abandonando a igreja. Estava um desastre a igreja, estava todo mundo indo embora porque a igreja estava chata. Parecia igreja de velho". Mas além desta falta de foco na cultura de juventude, Roberto mencionou outro elemento importante para explicar a frustração dos retornados: "Eles querem a perfeição que existe lá, mas não encontrarão em nenhum outro lugar”.

\section{EXCELÊNCIA, PERFEIÇÃO E O PRIMEIRO MUNDO}

Todos os entrevistados observaram que eles ficaram impressionados com a "excelência" da Hillsong. Excelência é parte do branding da megaigreja. Riches (2010) demonstrou que uma característica-chave da marca Hillsong é sua associação com a ideia de excelência. Além disso, em sua pesquisa sobre a Hillsong em Londres, Wagner (2013) demonstrou que esta ênfase na excelência associada à marca foi tão bem sucedida que as pessoas que frequentavam os cultos da Hillsong na cidade esperavam encontrar excelência musical e técnica. Wagner (2013, p. 107) explica que:

Embora a superprodução da Hillsong e igrejas similares tenha sido criticada como excessiva, a igreja responde dizendo que, para os participantes que experimentam a mais alta qualidade de produção de mídia em suas vidas cotidia- 
nas, nada menos do que este nível de produção será considerado amador e vai distraí-los do culto.

Excelência e perfeição são caras para os brasileiros, pois eles as associam com o mundo desenvolvido. Por outro lado, eles associam o Brasil com uma cultura do jeitinho (DAMATTA, 1991), de burlar leis, fazer as coisas pela metade, sem cuidado. Muitos brasileiros desejam deixar esta atitude para trás quando eles chegam à Austrália, pois sentem que esta é uma das causas do subdesenvolvimento de seu país. A Hillsong talvez possa ajudá-los nessa tarefa. Seguir regras, ser responsável e dar o melhor de si são coisas que eles aprendem ao servir na megaigreja e estudar no College. Patrícia, que estudou no College por um ano e hoje retornou à igreja dos pais, acha que essas qualidades negativas estão tão arraigadas na cultura brasileira que elas seriam um obstáculo para o estabelecimento da Hillsong no Brasil:

[Na Hillsong] eles têm uma mentalidade que é a "gringa", uma mentalidade de excelência no serviço, de comprometimento, uma mentalidade de que se você pega uma coisa para fazer, você tem que fazer bem feita, tem que dar satisfação do que você está fazendo. Isso é uma cultura que no exterior você tem e lá eles têm muito forte, eles ensinam aos alunos isso. Eu aprendi isso lá e tentei trazer um pouquinho para cá, só que o brasileiro não é assim. Ele quer ir ao cinema no domingo à noite; ele não vai ligar para o líder dele e falar "hoje eu não posso ir por causa disso, já conversei com o fulano que vai me substituir.” Não, ele falta. Chega na hora não tem ninguém lá. A Hillsong tem esses processos muito certinhos, daí vai chegar um monte de gente sem treinamento e não vai funcionar do jeito que eles querem, por isso que eu acho que eles estão demorando para abrir.

Marcos, outro jovem que está no momento estudando no College e está encarregado de ajudar os alunos brasileiros recém-matriculados, me disse que ele tinha uma lista com dez conselhos para eles:

Tentei fazer uma sessão de cultura, do tipo “o que precisamos mudar aqui”. Foi muito legal porque eu passei para eles de uma forma engraçada, mas seriam os "10 mandamentos brasileiros no College." Eu falei “número 1: seja amigo do seu despertador, nada de horário brasileiro aqui. Se a aula é às 14h3omin, esteja lá às $14 \mathrm{~h} 25 \mathrm{~min}$. Esteja 5 minutos antes, não atrase, até porque é cultura australiana também. Para a gente é socialmente aceitável você estar 5 ou 10 minutos atrasado". Aqui não, é desrespeitoso. Então não chegue atrasado. 
Em suas falas, Patrícia e Marcos sobrepõem as culturas da Austrália e da Hillsong. As duas são vistas como parte do mundo desenvolvido e possuem valores que os brasileiros necessitam aprender para tornarem-se também desenvolvidos. Tal como a Hillsong, a Austrália muitas vezes é idealizada no Brasil como um país perfeito e os seus cidadãos como cumpridores da lei por fazerem parte do Norte Global. Esta tendência começou após os Jogos Olímpicos de Sydney, em 2000, quando Austrália entrou pela primeira vez no imaginário brasileiro. Desde então o país está cada vez mais presente em reportagens e imagens positivas que circulam no Brasil. Estas imagens são criadas tanto por brasileiros na Austrália (nas redes sociais) e pela mídia brasileira, quanto pelo governo australiano. Por exemplo, já em 2002 a Folha de São Paulo publicou uma reportagem sobre brasileiros na Austrália. Uma das seções foi intitulada "Tudo funciona em Sydney, até o trânsito" e o repórter explica como não há engarrafamentos na maior cidade da Austrália. Certamente esta é uma construção derivada de um desejo pelo que o Brasil não possui: organização. Engarrafamentos são ocorrências comuns em Sydney e o transporte público é, de certa forma, pior do que em São Paulo (Sydney baseia-se em um sistema de ônibus e trens, e só agora está construindo seu metrô).

Por sua vez, o governo australiano tem feito um marketing forte para vender sua indústria de educação e turismo no Brasil. Ele organiza feiras anuais de educação que percorrem todo Brasil. A campanha de marketing empregada associa o sistema de educação "excelente" da Austrália com um estilo de vida descontraído e, para isto, usa imagens de suas praias, do interior (o chamado outback) e das grandes capitais. Nos últimos anos, também tem organizado um festival anual artístico em várias capitais. A embaixada australiana também seduz brasileiros, promovendo uma imagem positiva da Austrália em seu site do Facebook. Em suas postagens em português, a embaixada afirma continuamente que o país é um dos melhores lugares do mundo para se viver, com uma expectativa de vida excepcional e mostra lugares turísticos no país. É compreensível que o governo australiano faça este marketing, pois educação e turismo são bastante importantes para a sua economia ${ }^{5}$. Quando estas duas percepções idealizadas - da megaigreja e da Austrália - se sobrepõem, há uma forte atração que leva os brasileiros a desejarem

5 De acordo com o jornal australiano Financial Review, "As estatísticas mais recentes reforçam a posição da educação como o terceiro maior produto de exportação da Austrália (depois de carvão e minério de ferro), bem como sua posição como maior exportadora de serviços. Exportações do turismo também cresceram fortemente em 2015, em até 11\%, e chegaram a US \$15,8 bilhões, conforme os dados do ABS [Australian Bureau of Statistics]. Dados do Ministério da Educação demostram que havia aproximadamente 650.000 estudantes internacionais estudando na Austrália em 2015, um crescimento em 10\% em comparação com o ano anterior” (DoDD, 2016). 
ir para o país. Viajar a Sydney e ser capaz de servir ou estudar com cantores que são famosos em uma igreja da moda torna-se então um "sonho".

\section{UM CAMPO RELIGIOSO TRANSNACIONAL}

Podemos ver a formação de um campo religioso transnacional entre os dois países nos fluxos de ideias e pessoas que descrevi aqui. Para Levitt e Schiller (2004, p. 1009), campos sociais transnacionais são "um conjunto de várias redes de relações sociais interligadas, através do qual ideias práticas e recursos são desigualmente trocados, organizados e transformados". O conceito de campo religioso transnacional auxilia-nos a entender como instituições religiosas globais afetam o cotidiano dos migrantes, daqueles que ficam para trás e daqueles que retornam. Um campo religioso transnacional é circular, ao invés de ser de uma mão só. Como argumentou Sheringham (2013, p. 141), "as práticas religiosas dos imigrantes [...] na verdade borram as fronteiras entre o 'aqui' e 'lá', entre 'raízes' e 'rotas', entre o social e espiritual e são enviados em ambas as direções dentro de um espaço transnacional religioso".

Novas tecnologias da informação e comunicação (downloads de música, vídeos no YouTube, DVDs, CDs, redes sociais, blogs, o aplicativo da Hillsong), reportagens da mídia religiosa e secular, traduções de músicas por bandas brasileira cristãs famosas e a divulgação boca a boca ajudam a divulgar a Hillsong no Brasil e transformar a banda e a igreja em celebridades. Este status de celebridade leva muitos jovens cristãos brasileiros a sonhar em ir para a Austrália e estudar no Hillsong College. Para isto mudam suas vidas: eles pesquisam sobre o país e a igreja na internet, entram para comunidades de fãs nas redes sociais, se matriculam em cursos de inglês e começam a trabalhar para poupar dinheiro para a viagem.

Como outros imigrantes, uma vez que estão na Hillsong, eles aprendem uma cultura que vai mudar sua visão de mundo. A Hillsong é mais liberal no modo de vestir, no comportamento, incluindo beber, e até na teologia. Seus lemas: "Bem vindo a casa" e "Venha como estiver", são testemunhos desse desejo e dessa liberalidade. Para a megaigreja, isso facilita a entrada da pessoa na igreja e uma vez que ela o faça, o Espírito Santo se encarregará de mudar seu comportamento. Os estudantes entrevistados me disseram que a megaigreja é também mais centrada no amor e Jesus do que dinheiro e posses deste mundo, se comparada com as igrejas no Brasil. Quando os brasileiros postam suas fotos e experiências no Facebook, Instagram e blogs, e quando eles retornam ao Brasil e tentam aplicar o que aprenderam na Austrália, tornam-se vetores de remessas religiosas. Suas 
negociações com os pastores de suas Igrejas brasileiras e são exemplos de como os processos de encontro entre o global e o local ocorrem.

Robertson cunhou o conceito de glocalização para entendermos este encontro. Segundo ele a glocalização implica na dialética entre "a particularização do universal e a universalização do particular" (1992, p. 178). Nestas negociações dos retornados com suas igrejas e pastores vemos "como as tensões entre o local e o global acontecem levando à construção de identidades, práticas, visões de mundo e formas de organização híbridas" (VÁsquez; RochA, 2013, p. 21). Ao adotar e adaptar às condições locais algumas das práticas (agora globais) que estes retornados aprenderam na Hillsong, e as quais circulam globalmente dentro de mídia eletrônica e tradicional, essas igrejas brasileiras se tornam também híbridas.

\section{CONCLUSÃO}

Neste artigo investiguei os processos transnacionais que possibilitaram que a megaigreja australiana Hillsong abrisse uma filial em São Paulo. A posição periférica do Brasil na ordem mundial faz com que muitos brasileiros admirem e copiem o que vem dos países mais centrais, especialmente aqueles de língua inglesa. A intensificação dos processos de globalização nas últimas duas décadas fez com que o contato entre o Brasil e os centros metropolitanos produtores de cultura se tornasse mais acentuado. A Hillsong, com sua ênfase na cultura jovem e de celebridade, seu uso intenso de novas tecnologias de comunicação e informação, sua associação com a ideia de excelência e seu uso da língua inglesa, seduz jovens de classe média brasileiros. No imaginário desses jovens, a fascinação com a Hillsong se sobrepõe à admiração que existe no Brasil pela Austrália, vista como um país jovem, multicultural e tropical como o Brasil, mas que, no entanto, faz parte do "Primeiro Mundo". Por sua vez, o governo australiano também cria e estimula este imaginário de excelência em relação ao país, pois suas indústrias de educação e turismo dependem dele.

Assim, ir à Austrália e estudar no College ou frequentar os cultos da Hillsong tornam-se um sonho. Lá estes jovens têm a possibilidade de aprender a ser modernos (ao seguir o relógio e tornarem-se responsáveis) e cosmopolitas (ao aprender a falar inglês e fazer amizade com jovens do mundo inteiro). Entretanto, o retorno ao Brasil é tão ou mais penoso que para outros imigrantes, pois a igreja brasileira, que antes lhes oferecia uma comunidade e sentido de pertença, agora se torna um local hostil. Estes jovens voltam animados para mudar suas igrejas, mas os pastores não compreendem este desejo e não aceitam muitas de suas sugestões. 
Com vimos, as diferenças entre a Hillsong as igrejas pentecostais no Brasil são grandes e estes jovens acabam por sair de suas igrejas.

A chegada da Hillsong em São Paulo em outubro de 2016 e a tendência em copiar ideias e estratégias bem sucedidas dos países do Norte Global talvez transforme este cenário. Algumas igrejas pentecostais brasileiras já estão adotando certas características da megaigreja australiana, tais como o foco nos jovens e no culto espetáculo. Resta saber se isto é apenas uma mudança superficial ou se as transformações serão mais profundas, abrindo espaço para um pentecostalismo de classe média que não foca tanto no comportamento dos fieis e não faz uso abertamente no culto de rituais que não se adequam à sensibilidade de classe média (como exorcismos, falar em línguas, rituais de cura) (KoEHrSEN, 2016). Sem dúvida, podemos afirmar que o crescente fluxo de pessoas, ideias e práticas entre o Brasil e a Austrália, aqui analisado, demonstra a construção de um campo religioso transnacional entre os dois países que dará frutos significativos no campo religioso brasileiro num futuro próximo.

\section{REFERÊNCIAS BIBLIOGRÁFICAS}

AEI. “Student Enrolment Data 2011". Australian Education International. Disponível em: https://internationaleducation.gov.au/research/International-Student-Data/ Documents/INTERNATIONAL\%2OSTUDENT\%2ODATA/2011/2011Dec_0712.pdf. Acesso em: 21 de agosto de 2012.

Bourdieu, Pierre. "The Forms of Capital." In: Handbook of Theory and Research in the Sociology of Education. Westport, CT: Greenwood Press, 1986, p. 241-258.

CCBV (Conselho de Cidadãos Brasileiros em Vitória). "O Brasileiro em Victoria, Austrália”. Relatório de Pesquisa. Melbourne: 2016.

Chagas, Tiago. "Convertida? Bruna Marquezine vai a culto da Hillsong in Los Angeles acompanhada da modelo Stephannie Oliveira”. Gospel Mais, 20 de agosto de 2014. Disponível em: https://noticias.gospelmais.com.br/bruna-marquezine-hillsongstephannie-oliveira-70546.html. Acesso em: 22 de fevereiro de 2016.

DaMatta, Roberto. O Que Faz o Brasil, Brasil? Rio de Janeiro: Rocco, 1984.

.Carnivals, Rogues, and Heroes: An Interpretation of the Brazilian Dilemma.

Indiana: University of Notre Dame Press, 1991.

DET (Department of Education and Training). "International Student Numbers 2015”. Research Snapshots. Fevereiro de 2016. Disponível em: https://internationaleducation. gov.au/research/Research-Snapshots/Documents/Student\%20Numbers\%202015. pdf. Acesso em: 10 de abril de 2016. 
DodD, Tim. "Education revenue soars to become Australia’s $\$ 20$ billion export". Financial Review, Sydney, 3 de fevereiro de 2016. Disponível em: http://www.afr.com/news/ policy/education/education-revenue-soars-to-become-australias-20-billion-export20160203-gmke3k\#ixzz47Yr4uqD2. Acesso em: 3 de maio de 2016.

Duarte, Fernanda. "Living in 'the Betweens': Diaspora Consciousness Formation and Identity among Brazilians in Australia”. Journal of Intercultural Studies, n. 26, p.315-335, 2005 .

Freston, Paul. Evangelicals and Politics in Asia, Africa and Latin America, Cambridge: Cambridge University Press, 2004.

"The Transnationalisation of Brazilian Pentecostalism: The Universal Church of the Kingdom of God". In: Corten, André ; Marshall-Fratani, Ruth (Orgs.) Between Babel and Pentecost: Transnational Pentecostalism in Africa and Latin America. London: C. Hurst \& Co, 2001, p. 196-215.

Hess, David J.; DaMatta, Roberto. The Brazilian Puzzle: Culture on the Borderlands of the Western World. New York: Columbia University Press, 1995.

KoeHrsen, Jens. Middle-Class Pentecostalism in Argentina: Inappropriate Spirits. Leiden: Brill, 2016.

LevitT, Peggy. "Social Remittances: A Local-Level, Migration-Driven Form of Cultural Diffusion”. International Migration Review. n. 32, p. 926-48, 1998.

Levitt, Peggy; Schiller, Nina. "Conceptualising Simultaneity: A Transnational Social Field Perspective on Society”. The International Migration Review, n. 38, p. 10021039, 2004.

Mariano, Ricardo. “Império Universal”. Folha de São Paulo, Caderno Mais, São Paulo, 5 de fevereiro de 2010, p. 4.

MRE (Ministério das Relações Exteriores). "Estimativas populacionais das comunidades brasileiras no Mundo, 2014 (números atualizados em 28/o8/2015)”. Brasileiros no Mundo. Disponível em: http://www.brasileirosnomundo.itamaraty.gov. br/a-comunidade/estimativas-populacionais-das-comunidades/estimativaspopulacionais-brasileiras-mundo-2014/Estimativas-RCN2014.pdf. Acesso em: 30 de maio de 2016.

Novaes, Luana. "Hillsong Church São Paulo poderá ser inaugurada no início de 2016". Guiame, 13 de maio de 2015. Disponível em: http://guiame.com.br/gospel/mundocristao/hillsong-church-sao-paulo-podera-ser-inaugurada-no-final-de-2015.html. Acesso em: 13 de março de 2016.

Riches, Tanya. Shout To The Lord! Music and change at Hillsong: 1996-2007. Dissertação (mestrado). Australian Catholic University. Sydney, 2010.

Robertson, Roland. Globalization: Social Theory and Global Culture. London: Sage, 1992. 
RochA, Cristina. "Two Faces of God: Religion and Social Class in the Brazilian Diaspora in Sydney". In: Kumar, Pratap (Org.) Religious Pluralism in the Diaspora. Leiden: Brill, 2006, p. 147-160.

“The Brazilians in Sydney”. The Dictionary of Sydney/ Sydney Journal, n. 1, p. 79-80, 2008.

. "Conexiones Sur-Sur: Vivir entre Australia y Brasil". In: SolÉ, Carlota et al. (Orgs.) Nuevos Retos del Transnacionalismo en el Estudio de las Migraciones. Barcelona: Ministerio de Trabajo e Imigración, p. 113-127, 2009.

. "Transnational Pentecostal Connections: an Australian Megachurch and a Brazilian Church in Australia”. Pentecostudies, n. 12, p. 62-82, 2013.

"Triangular Circulation: Japanese Brazilians on the move between Japan, Australia and Brazil”. Journal of Intercultural Studies, n. 35, p. 493-512, 2014.

Sheringham, Olivia. Transnational Religious Spaces: Faith and the Brazilian Migration Experience. Basingstoke: Palgrave Macmillan, 2013.

Sallas, Ana; Bega, Maria. "Juventude, Cultura e Política". Apresentado no $13^{\circ}$ Congresso Brasileiro de Sociologia, Recife, 29 de maio a 1 de junho, 2007.

Strazzery, Jerry. "Hillsong College”. Brazil-Australia Blog, 11 de setembro de 2011. Disponível em: http://www.brazilaustralia.com/hillsong-College. Acesso em: 13 de setembro de 2011.

VÁsquez, Manuel; Rocha, Cristina. "Introduction: Brazil in the New Global Cartography of Religion”. In: VÁsquez, Manuel; Rocha, Cristina (Orgs.) The Diaspora of Brazilian Religions. Leiden: Brill, 2013, p. 1-42.

Wagner, Thomas J. Hearing the Hillsong Sound: Music, Marketing, Meaning And Branded Spiritual Experience at a Transnational Megachurch. Tese (doutorado). Royal Holloway University of London. Londres, 2013.

WulfHorst, Cristina. Intimate Multiculturalism: Blurring Boundaries between Brazilians and Australians in Sydney. Tese (doutorado). Western Sydney University, Sydney, 2011.

"The Other Brazilians: Community Ambivalences among Brazilians in Sydney”. Journal of Intercultural Studies, n. 35, p. 475-492, 2014.

Recebido para publicação em: 30/10/2016. Aceito para publicação em: 03/11/2016. 